\title{
Factors associated with influenza vaccination compliance at a tertiary care teaching hospital in Argentina
}

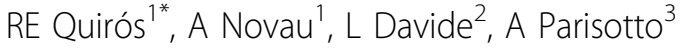 \\ From 3rd International Conference on Prevention and Infection Control (ICPIC 2015) \\ Geneva, Switzerland. 16-19 June 2015
}

\begin{abstract}
Introduction
After pandemic influenza A H1N1 in 2009, an increase in influenza vaccination compliance among healthcare personnel was evident in all care settings. However, these levels could not be sustained over time. Although different variables are associated with the level of compliance to influenza vaccination, these have not been evaluated at institutional level in our country. Their identification could allow adjustments in influenza vaccination campaigns in order to increase its compliance.
\end{abstract}

\section{Objectives}

To identify factors associated with influenza vaccination compliance during a multiyear period of intervention.

\section{Methods}

A retrospective observational study, at a 142-bed tertiary care teaching hospital, was conducted to evaluate those factors associated with influenza vaccination compliance. All staff who worked for at least four years between March 2010 and June 2014 was included in the study. As influenza vaccination is mandatory for staff in our institution, Department for Infection Prevention and Control implemented annual campaigns to increase the compliance with this recommendation based on brochures, reminders and vaccination in the workplace.

\section{Results}

There were 6,612 opportunities of influenza vaccination with an overall compliance of $75.8 \%$ (95\% CI 74.8\% $76.9 \%)$. Significant differences in compliance were observed between ancillary staff (94.0\%), nurses (91.7\%),

Prevention and Infection Control Department, Hospital Universitario Austral, Pilar, Argentina

Full list of author information is available at the end of the article and physicians (50.9\%). Females have better compliance (83.2\%) than males (62.8\%), and employees (87.5\%) than contract personnel (46.8\%). Influenza vaccination decrease significantly from age 19 - 29 years $(90.7 \%)$ to age $\geq 60$ years $(53.5 \%)$. Except sex, the remaining variables persisted in the controlled multivariate model for compliance. The overall rate of compliance decreased from $76.9 \%$ in the first year of vaccination to $71.4 \%$ in the final year, reaching a peak of $82.2 \%$ in the second year.

\section{Conclusion}

Despite an acceptable level of compliance immediately after the pandemic, the study allowed to demonstrate a significant reduction in vaccination rates in recent years. Since, medical staff, and contract personnel represent the groups with less influenza vaccination compliance, target strategies should be developed to improve the compliance of future influenza vaccination campaigns.

\section{Disclosure of interest}

None declared.

\section{Authors' details}

${ }^{1}$ Prevention and Infection Control Department, Hospital Universitario Austral, Pilar, Argentina. ${ }^{2}$ Pharmacy Department, Hospital Universitario Austral, Pilar, Argentina. ${ }^{3}$ Nursing Department, Hospital Universitario Austral, Pilar, Argentina.

Published: 16 June 2015

\section{doi:10.1186/2047-2994-4-S1-P92}

Cite this article as: Quirós et al:: Factors associated with influenza vaccination compliance at a tertiary care teaching hospital in Argentina. Antimicrobial Resistance and Infection Control 2015 4(Suppl 1):P92. 